\title{
Magnetic Shielding as Core material in Planar Inductors
}

\author{
Nielsen, Alex; Jørgensen, Anders; Ouyang, Ziwei
}

Published in:

Proceedings of $47<$ sup $>$ th $</$ sup $>$ Annual Conference of the IEEE Industrial Electronics Society

Link to article, DOI:

10.1109/IECON48115.2021.9589704

Publication date:

2021

Document Version

Peer reviewed version

Link back to DTU Orbit

Citation $(A P A)$ :

Nielsen, A., Jørgensen, A., \& Ouyang, Z. (2021). Magnetic Shielding as Core material in Planar Inductors. In Proceedings of $47^{7}$ Annual Conference of the IEEE Industrial Electronics Society IEEE.

https://doi.org/10.1109/IECON48115.2021.9589704

\section{General rights}

Copyright and moral rights for the publications made accessible in the public portal are retained by the authors and/or other copyright owners and it is a condition of accessing publications that users recognise and abide by the legal requirements associated with these rights.

- Users may download and print one copy of any publication from the public portal for the purpose of private study or research.

- You may not further distribute the material or use it for any profit-making activity or commercial gain

- You may freely distribute the URL identifying the publication in the public portal 


\section{Magnetic Shielding as Core material in Planar Inductors}

\author{
$1^{\text {st }}$ Alex Nielsen \\ Electrical Engineering \\ Technical Universisty of Denmark \\ Lyngby, Denmark \\ s173946@dtu.dk
}

\author{
$2^{\text {nd }}$ Anders Jørgensen \\ Electrical Engineering \\ Technical Universisty of Denmark \\ Lyngby, Denmark \\ s173943@dtu.dk
}

\author{
$3^{\text {rd }}$ Ziwei Ouyang \\ Electrical Engineering \\ Technical Universisty of Denmark \\ Lyngby, Denmark \\ zo@elektro.dtu.dk
}

\begin{abstract}
Inductors with small footprints and low profile are vital to the development of high density converters with optimal power conversion, inductors that can embedded should be considered as they provide excellent characteristics. This paper investigates a type of planar magnetic inductor which uses magnetic shielding over an air inductor, instead of using a regular core material. A synchronous buck-boost DCDC converter is built to verify the effectiveness of the semishielded inductor compared to the planar inductor. Furthermore, inductance characteristics are investigated, using the MadMix inductor test system.
\end{abstract}

Index Terms-DC-DC converter, planar inductor, semi shielded inductor, smps, magnetic materials

\section{INTRODUCTION}

Modern society rely heavily on increasingly dense and efficient power electronics, these power electronics commonly come in the shape of switch mode power supplies (SMPS). Inorder to obtain high power density and high efficiency, SMPS use high-frequency switching, which can reduce component size on mainly inductors and capacitors. Furthermore, the industry is seeing a push towards new inductor implementations, namely planar magnetic components[1]. Planar magnetic are easily integrated on a printed circuit board (PCB), and is therefore cheaper to produce and usually also offers more flexibility for the overall design.

In this paper two planar magnetic structures are designed using finite element analysis (FEA), fabricated and tested using the MadMix Inductor test system[2]. Furthermore, the two inductors are tested on the same synchronised buckboost setup. In order to use the same buck-boost setup, the two inductors are designed to be stand-alone and mounted in a sandwich structure[3]. The first inductor is a standard planar inductor with a magnetic core, this is a common planar inductor structure which is used to compare to the second inductor. The second inductor that is analysed is a effectively an air-core which uses RF-shielding to reduce noise and short circuit eddy current, it is referred to as an semi-shielded inductor in this paper. The goal of the paper is to provide a clear and comprehensive overview of the pros and cons of the semi-shielded inductor, compared to the planar magnetic core inductor.

How the planar and semi-shielded inductor can be seen in figure 1.

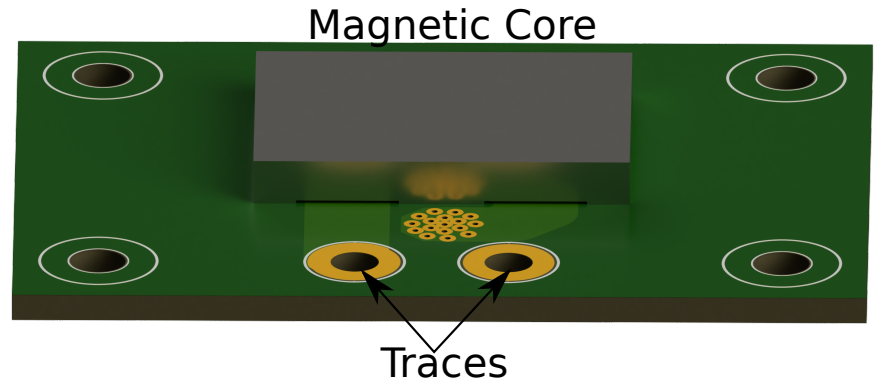

(a) Planar inductor Magnetic Shielding

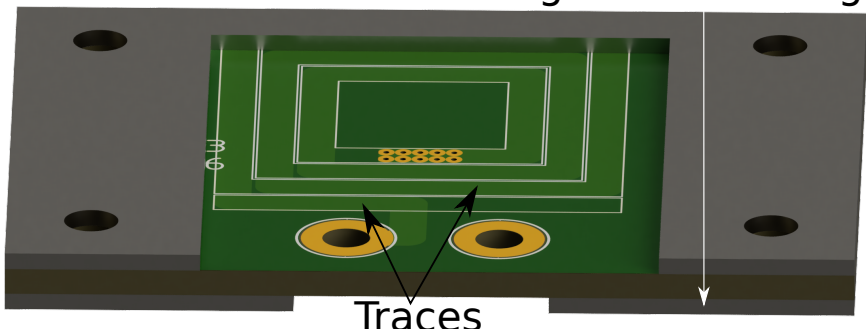

(b) Semi Inductor. The magnetic shielding have been remove over the coil to show the PCB traces.

Figure 1: Pictures of the two type of inductors.

\section{BUCK-BOOST CIRCUIT}

In this paper a synchronised buck-boost converter is used to test the inductor design example. Therefore, a short introduction is presented for reference.

\section{A. Synchronised Buck-Boost Power Stage}

The switching part of the power stage consist of two switching field-effect transistor (FET)s, and two synchronised rectifying FETs which act as ideal diodes. As the inductors are the main focus of this paper, the circuit operation is not analysed. Furthermore, this has been covered in several other papers [4]-[6]. Nevertheless, the power stage is shown in figure 2 . 


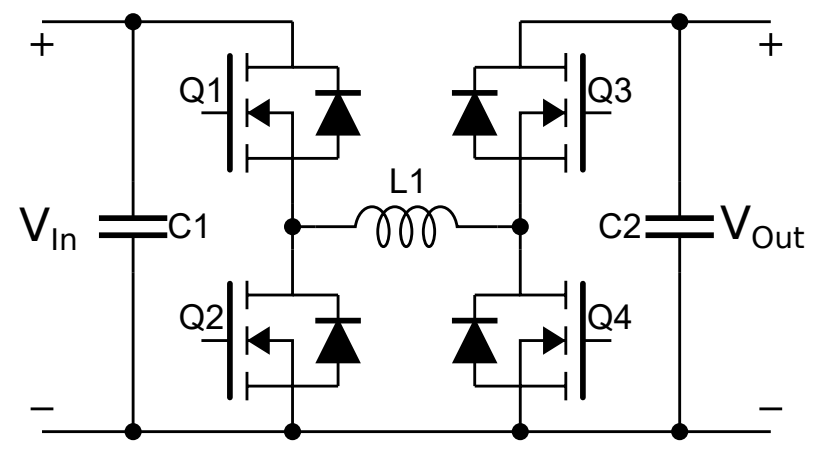

Figure 2: Power stage of a synchronised buck-boost converter

As the converter is used in both buck and boost operation, the inductors minimum value should be designed after the maximum value of equations (1) and (2).

$$
\begin{aligned}
L_{\text {Buck }} & \geq \frac{V_{\text {out }} \cdot\left(V_{\text {in,max }}-V_{\text {out }}\right)}{F_{\text {sw }} V_{\text {in,max }} \Delta I} \\
L_{\text {Boost }} & \geq \frac{V_{\text {in }, \text { min }}^{2} \cdot\left(V_{\text {out }}-V_{\text {in }, \text { min }}\right)}{F_{\text {sw }} V_{\text {out }}^{2} \Delta I}
\end{aligned}
$$

Note that the equations in (1) and (2) use a greater or equal sign, as the inductor value can be larger than the calculated value. Using a larger value will however result in a larger resistance for the inductor, as the windings are longer, this must be taken into consideration.

\section{EMBEDDED CONVERTER CONSIDERATIONS}

When designing a modern SMPS, traditional wire-wound inductor have a large footprint and take up a lot of vertical space. As the industry is generally trending towards higher frequency converters and therefore, smaller passive components using traditional inductors becomes disadvantages. At a certain point even planar inductors using a planar magnetic core can take up a significant amount of space, as the core is usually taller than the rest of the components on the PCB. Depending on the mechanical specification, i.e. dimensions, different planar inductor designs need to be considered. This paper aims for a relatively small footprint and a low overall profile, which is achieved by using a sandwich structure for the converter.

Other than component size thermal handling is usually another limiting factor for an SMPS, but here new component types such as gallium nitride field-effect transistor (GaNFET) provide better characteristics. GaNFET's have lower $R_{d s(\text { on })}$ than most traditional metal-oxide-semiconductor field-effect transistor (MOSFET), while also having significantly faster switching capabilities and a smaller footprint. Faster rise and fall times and lower $R_{d s(o n)}$ leads to lower overall loss in the switching components. There is, however, one significant drawback on GaNFETs as they usually have a lower $V_{g s}$ tolerance. Therefore, the controller must be suited for this application, which means it should not bootstrap the gate voltage, as this will (commonly) lead to a $V_{g s}$ out of spec. The lower power loss in the GaNFETs allow the overall converter design to shrink, which leads to the added benefit of minimising the length gate loops and current paths.

\section{A. Low profile inductors}

Depending on the application for a converter, integrated cores might not be low profile enough. Therefore, in recent years steps have been taken to laminate various core materials into the PCBs themselves[7], or make various sandwich structures[8] meant to increase power density. There are however one main disadvantage to both of these technologies, namely the price. The inductor with the laminated core uses a technology that is not commonly available, which increases the cost of manufacturing. While the sandwich structure uses commonly available technologies, there are many small pieces which adds up in cost and design time. Therefore, an inductor which uses cheap manufacturing technologies and cheap materials, would be advantages to other low profile inductors. The semi-shielded inductor proposed in this application, uses off the shelf materials and standard manufacturing technologies. Furthermore, it has several advantages, other than the price point. The advantages can be summarised as follows:

1) Cheap - regular 1 or $2 \mathrm{oz}, 2$ layer PCB can be used for the windings, these are extremely cost efficient. This has the added benefit of allowing for multiple designs to be made in the prototyping phase, as it does not add a substantial cost.

2) Very low profile - the inductor is very low profile due to it consisting of a PCB and a magnetic shielding sheet. PCBs are usually $1.6 \mathrm{~mm}$ thick, while the magnetic shielding comes in different thickness from 0.05 to 1 $\mathrm{mm}$, although thicker magnetic shielding is desired due to saturation.

3) Easy and flexible design - design is easily done in (any) modern electronics computer-aided design (CAD) program, furthermore, it is easily changeable at very low design cost. If the inductor is integrated, i.e. on the same board as the controller, then it might be able to be designed to take excess space. Symmetry considerations for the inductor has however not been analysed for this paper, so this might not be feasible.

There is however one main drawback for the semi-shielded inductor, as it is hard to design without FEA. Furthermore, as the magnetic shielding sheets are aimed for low power noise suppression, the producers of these sheets normally only provide the magnetic permeability in relation to frequency.

\section{B. Inductor Design using FEA}

Conventional inductor design can be done using equations that have been known for many years[9]. Planar magnetic components are, however, somewhat more difficult to design using 'hand calculations' as there are many approximations that are needed in order to do the 'hand calculations'. One of theses approximations is the mutual inductance between the traces of the inductor[10]. Therefore, computer aided and automated calculations can be used, i.e. FEA. FEA can be used to simulate many iteration of the same or different inductor 
under various conditions, this helps paint a more full picture of how the real inductor will perform.

The calculation for the semi inductor could be done in without FEA as it is a planar air core, however, as soon as the magnetic shielding is added around the inductor, the inductance will increase. So to simplify and getting a more accurate results for the inductor design, this paper will use FEA to design the semi-shielded inductor.

With using FEA can there also be make improvements for the inductor to increases the inductance, quality factor or the resistance of the inductor.

\section{DESIGN EXAMPLE}

As a complement to the proposed inductor design and design method, a design example is provided.

\section{A. Specification}

The inductors are modelled to fit an synchronised buckboost converter which uses the specification shown in table I.

Table I: Buck-boost specification

\begin{tabular}{|c|c|r|c|}
\hline & Symbol & Value & Unit \\
\hline Input voltage & $V_{\text {in }}$ & 8 to 15 & $\mathrm{~V}$ \\
\hline Output voltage & $V_{\text {out }}$ & 12 & $\mathrm{~V}$ \\
\hline Output current & $I_{\text {out }}$ & 5 & $\mathrm{~A}$ \\
\hline Switching frequency & $F_{s}$ & 600 & $\mathrm{kHz}$ \\
\hline Inductor ripple current & $K_{\text {ind }}$ & 40 & $\%$ \\
\hline Output voltage ripple & $\Delta V$ & 100 & $\mathrm{mV}$ \\
\hline
\end{tabular}

The chosen specification is rated at a maximum of $60 \mathrm{~W}$, and this is the value which is subsequently used when calculating power densities. The power rating is used to pick the power stage components and design the inductors. Using the values given in table I the minimum value for the inductor can be found using equation (1) and (2). The minimum inductor value is found in the buck region, given at approximately $2 \mu \mathrm{H}$, a larger value will work as well.

\section{B. Inductor design}

The inductors are simulated in Maxwell 3D, and only one example per inductor type is covered here. For the planar inductor an E22/6/16 with the N87 material was chosen. It was found that only two turns were needed to get approximately $2.2 \mu \mathrm{H}$, when the air-gap was $0.1 \mathrm{~mm}$, i.e. the approximate thickness of a piece of paper. Using two turns on a two sided PCB result in a very low resistance, as the traces can be $5 \mathrm{~mm}$ wide.

The semi-shielded inductor was designed as a square spiral on a two layer PCB, with 5 turns on either side for a total of 10 turns. The magnetic shielding is a $1 \mathrm{~mm}$ thick EFR material from KEMET, this material does however not have a B-H curve specified. Therefore, a similar material called $\mathrm{Mu}-$ Metal was used in the simulation, this results in some minor deviations which are covered in section $\mathrm{V}$. The simulated values are summarised in table III.
Table II: Simulated values for the inductance @ $600 \mathrm{kHz}, \mathrm{AC}$ resistance and DC resistance

\begin{tabular}{|c|c|c|c|}
\hline & $\mathrm{L}[\mu \mathrm{H}]$ & $R_{A C}[m \Omega]$ & $R_{D C}[m \Omega]$ \\
\hline Planar & 2.23 & 160 & 29.3 \\
\hline Semi & 2.01 & 317 & 100 \\
\hline
\end{tabular}

\section{Converter layout}

For testing the inductors, a buck-boost converter was designed to fit the specification previously introduced. The converter layout is the same for both of the inductors, so the efficiency results can be compared. As previously mentioned the converter is made in a sandwich structure, as this provides a small footprint with an low profile.

The controller is a LT8390 from Analog Devices[11]. This controller was chosen as it does not use bootstrapping, instead it uses an internal $5 \mathrm{~V}$ voltage reference, which works in conjunction with GaNFETs. On the high side FETs the gate voltage is $V_{s}+5 \mathrm{~V}$. The GaNFETs chosen for this example are EPC2045[12], as their small size and power ratings fit this application.

The converter is designed to be able to mount different inductors. This was done by placing two solders pads on both the controller PCB and the inductor PCB, with these a wire can be solder on both pads for connecting the controller PCB and the inductor PCB. The sandwich structure for the converter(s) can be seen in figure 3 and 4. Figure 5 and figure 6 shows the finalised PCB.

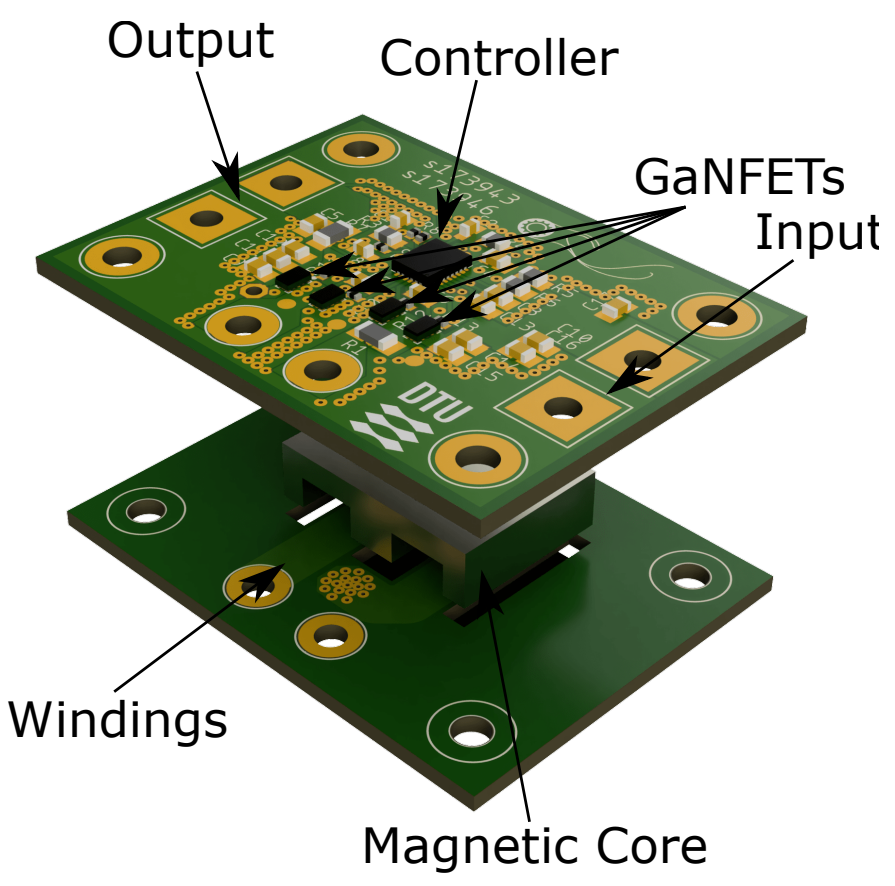

Figure 3: Rendering of planar inductor PCB structure. 


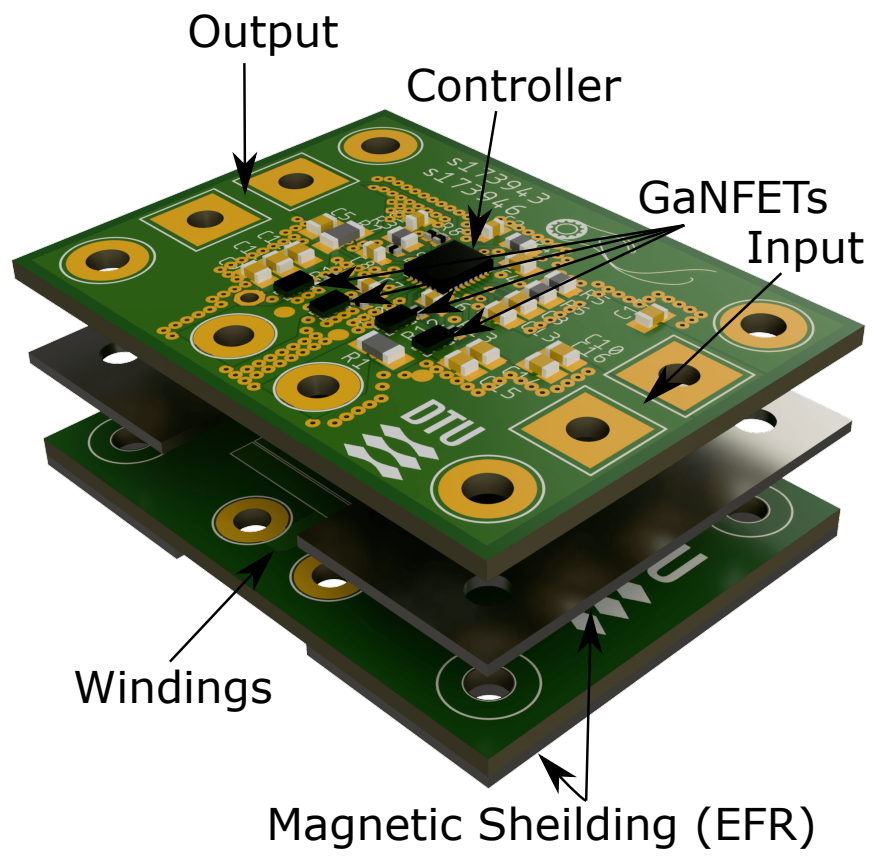

Figure 4: Rendering of semi-shielded inductor PCB structure.

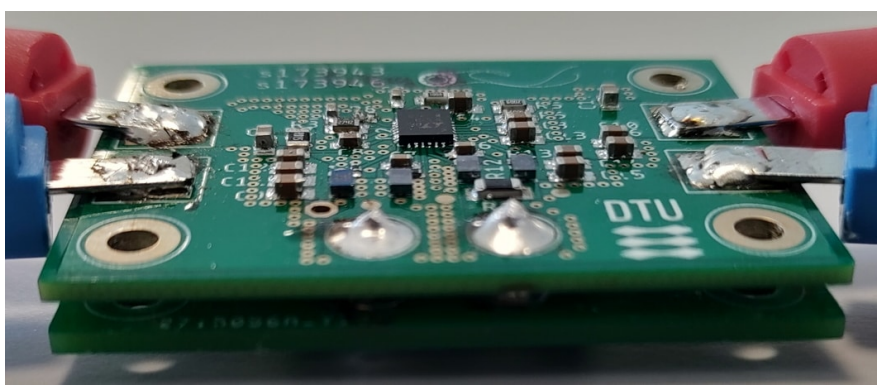

Figure 5: Finalised PCB of the inductor test board and the planet inductor.

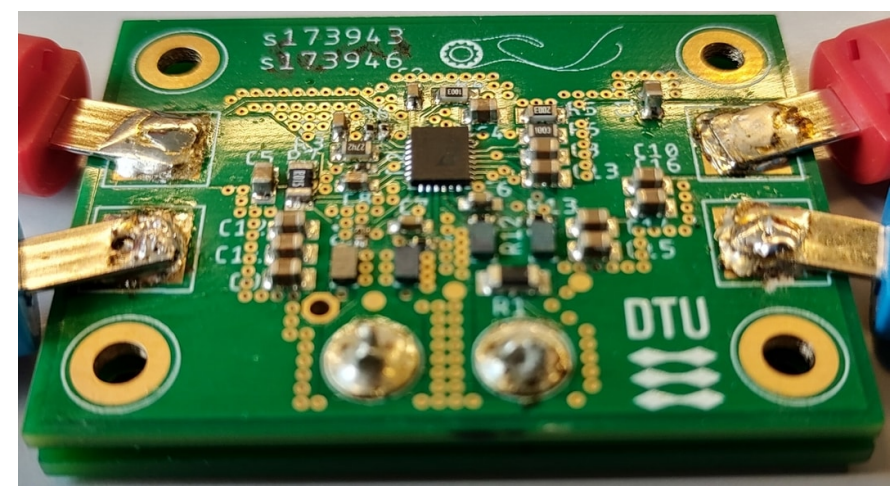

Figure 6: Finalised PCB of the inductor test board and the planet inductor.

\section{RESULts}

This section describes the main points of interest for the design example inductors.

\section{A. Measured values}

The simulated values verified by using value obtained from the MadMix Inductor test system[2].

Table III: Usable measured values for the inductance @ $600 \mathrm{kHz}, \mathrm{AC}$ resistance and DC resistance at normal operation.

\begin{tabular}{|c|c|c|c|}
\hline & $\mathrm{L}[\mu \mathrm{H}]$ & $R_{A C}[m \Omega]$ & $R_{D C}[m \Omega]$ \\
\hline Planar & 2.223 & 29.45 & 11.94 \\
\hline Semi & 2.005 & 159 & 104.8 \\
\hline
\end{tabular}

\section{B. Inductance vs current}

As the inductors are to be used in power application, one point of interest is core saturation. Due to the large amount of core material, the planar inductor will not saturate for this application. It was however discovered that the semi-shielded inductor will experience 'soft saturation' at approximately 5 A of current. This can be simulated as shown in figure 7, it should be noted that the simulation is from 0 to $10 \mathrm{~A}$, this is to properly show the saturation effect.

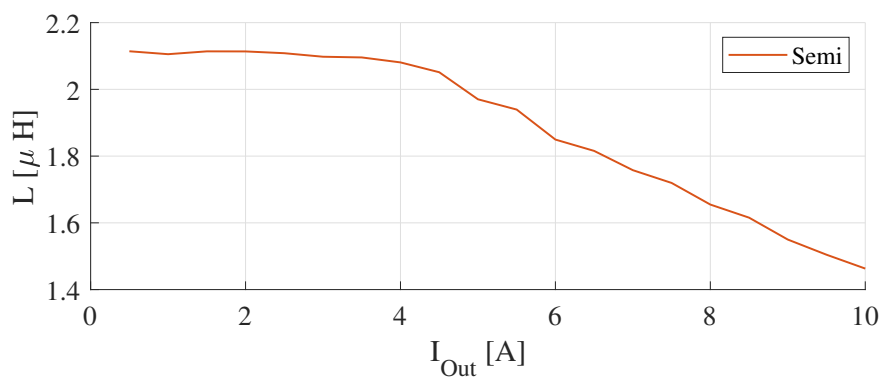

Figure 7: Simulation results of the Semi Shielded inductor in Maxwell 3D.

The simulation can be compared to values measured using the MadMix Inductor test system. These results is shown in figure 8 . The same measurement were also done for the planar inductor. Comparing the measured values for the semi-shielded with the simulations, it can be seen that the soft saturation start at a lower current compared to the measured values. This is most likely due to the simulation not using the exact material that are used in the real world. As previously mentioned the simulation used $\mathrm{Mu}$ metal as the EFR shielding manufacture does not provide a B-H curve.

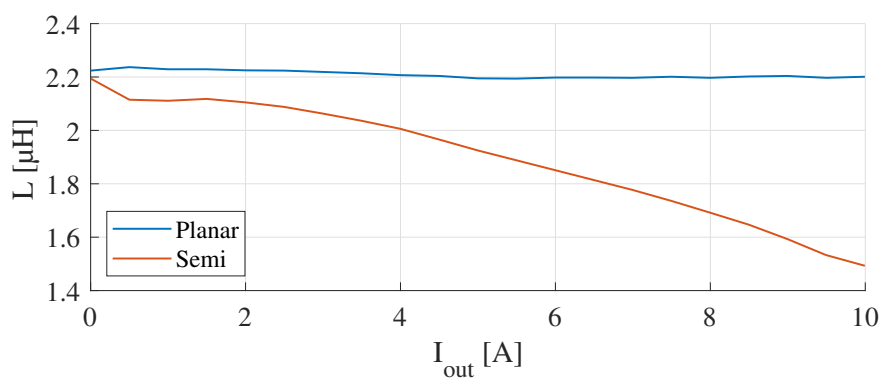

Figure 8: Inductance over output current. 
Furthermore, due to the resistance of the semi-shielded inductor, the temperature was at approximately $100^{\circ} \mathrm{C}$ at 8 10 A. The EFR datasheet specify the material for -40 to $105^{\circ} \mathrm{C}$, so this material might not be suited for high current applications on this inductor.

\section{Efficiency}

Another point of comparison for these two inductors, is the efficiency in a converter, in this case the designed buck-boost converter. Figure 9, 10 and 11, shows the efficiency of the two inductors in the converters with an input voltage of $8 \mathrm{~V}, 13 \mathrm{~V}$ and $15 \mathrm{~V}$. For the most part of the different output power levels, the planar inductor is clearly better then the semi inductor, which is likely due to the significantly lower resistance.

Except, at $15 \mathrm{~V}$ input and $12-25 \mathrm{~W}$ output, here they have the same efficiency. Knowing the link between current and inductance from the previous experiments, this could possibly be explained by the converter being in the buck region, which results in a lower current through the inductor which means it has an easier time maintaining its inductance.

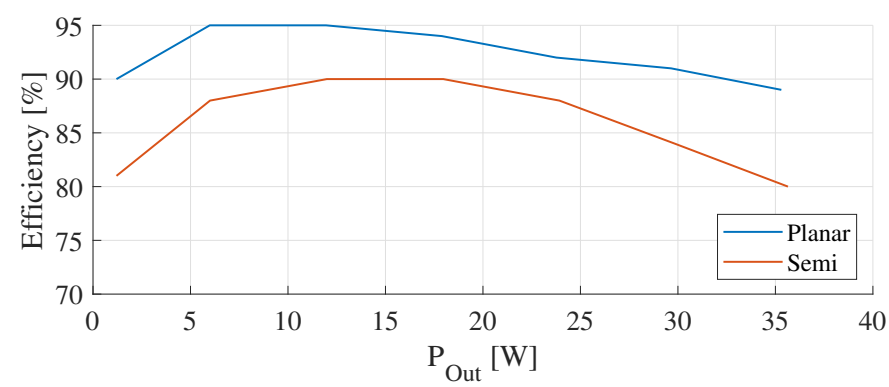

Figure 9: Efficiency at $V_{i n}=8 \mathrm{~V}$. The output power is only up to $35 \mathrm{~W}$ as the power supply used for the experiments could not deliverer more then $60 \mathrm{~W}$ for the converter.

As the current in the boost region is significant higher than in the buck region, it was not possible to measure the full desired $60 \mathrm{~W}$ of power for $V_{i n}=8$.

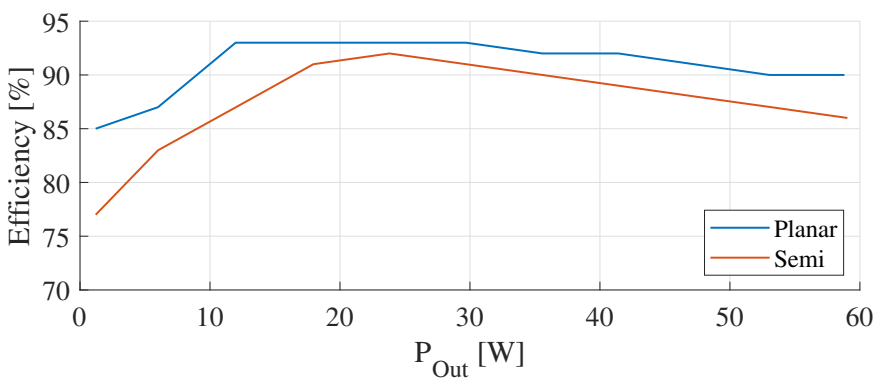

Figure 10: Efficiency at $V_{i n}=13 \mathrm{~V}$

When operating the semi-shielded converter at higher power $\left(>50 \mathrm{~W}\right.$ ) the temperature of the inductor is over $90^{\circ} \mathrm{C}$ (ambient $25^{\circ} \mathrm{C}$ ), so as previously mentioned the converter might not be suited for high current operation. Furthermore, due to the sandwich structure the control PCB also heat up significantly, which effectively increases the controller and GaNFETs ambient temperature. During testing it became clear that thermal management when using the semi-shielded inductor, is most likely the biggest problem in a real world application, as the planar inductor core was only $50^{\circ} \mathrm{C}$ at peak power.

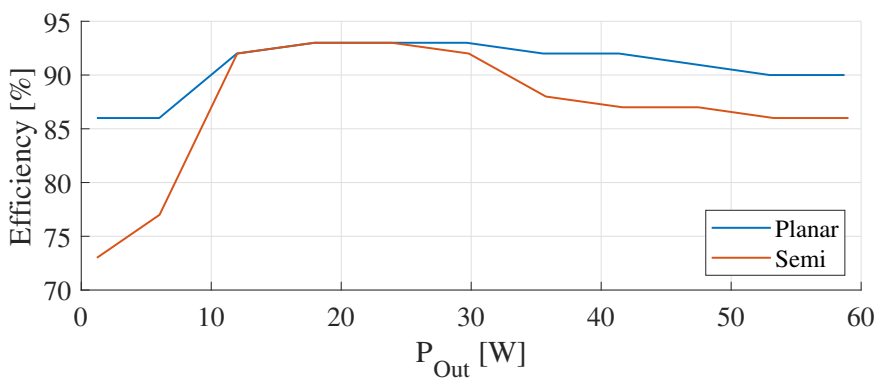

Figure 11: Efficiency at $V_{i n}=15 \mathrm{~V}$

\section{Power density}

Finally the power density of the converter can be considered, for this the full width, length and height is used. Furthermore, the 'effective' density is also calculated, this means excluding everything that is technically not necessary for the converter, such as the input/output connections which are oversized and the mounting holes. The dimensions and densities are summarised in table IV.

Table IV: Power densities at peak power of $60 \mathrm{~W}$.

\begin{tabular}{|c|c|c|c|c|c|c|c|c|}
\hline \multirow{2}{*}{} & \multicolumn{2}{|c|}{$\begin{array}{c}\text { Width } \\
{[\mathrm{mm}]}\end{array}$} & \multicolumn{2}{c|}{$\begin{array}{c}\text { Length } \\
{[\mathrm{mm}]}\end{array}$} & \multicolumn{2}{c|}{$\begin{array}{c}\text { Height } \\
{[\mathrm{mm}]}\end{array}$} & \multicolumn{2}{c|}{$\begin{array}{c}\text { Power density } \\
{\left[\mathrm{W} / \mathrm{in}^{3}\right]}\end{array}$} \\
\cline { 2 - 9 } & act. & eff. & act. & eff. & act. & eff. & act. & eff. \\
\hline Planar & 37 & 34 & 50 & 35 & 11.7 & 10.1 & 45.4 & 81.8 \\
\hline Semi & 37 & 34 & 50 & 35 & 6.7 & 6.7 & 79.3 & 123.3 \\
\hline
\end{tabular}

It is clear that the power density of the semi-shielded inductors converter is significantly better than the planar inductors converter. This planar inductors converter is slightly better if the core was the 'perfect' height to accommodate the single 1.6 $\mathrm{mm}$ PCB. However, due to the thermal aspects of the semishielded inductor, it might not be suited for prolonged use, especially in tight spaces where low profile is needed.

\section{CONSIDERATION FOR FUTURE DESIGN}

\section{A. More efficient semi-shielded inductor}

The efficiency of the semi inductor can be increased by changing the copper thickness of the PCB traces. The layout of the wires could also be change to be a symmetrical spiral inductor[13] instead of the asymmetrical as it is right now. The benefits of a symmetrical spiral inductor is it can use less space and also improving the quality factor. An problem by using a symmetrical spiral inductor is that the spiral can only be placed on one side of a 2 layer $\mathrm{PCB}$ as the second side must be used for the underpasses of the traces. This problem can be prevented by using 4 layer PCB instead of 2 layer so the underpasses can be placed on the middle layers of the PCB. The symmetrical spiral is mostly commonly found in integrated circuit (IC) design and is not talk much for PCB designs. 


\section{CONCLUSION}

This paper introduces and investigates a planar inductor structure, which relies on magnetic shielding to store energy. The value of using FEA for designing planar inductors is discussed, and a use case is done. On the basis of simulations, measurements using both a synchronised buck-boost converter and an inductor test system, the characteristics of the inductor is discussed. Two inductor prototypes are produced and compared, using the same converter.

\section{REFERENCE}

[1] Z. Ouyang and M. A. Andersen, „Overview of planar magnetic technology - Fundamental properties“, IEEE Transactions on Power Electronics, vol. 29, no. 9, pp. 4888-4900, 2014, ISSN: 08858993. DOI: 10.1109/ TPEL.2013.2283263.

[2] MadMix, „Accurate Inductor Measurement System“,

[3] Philips Magnetic, „Planar E cores Planar E cores“, pp. 250-252, 1997.

[4] B. Sun, „Multimode control for a four-switch buckboost converter", Analog Design Journal : Power, pp. 1-6, 2019. [Online]. Available: http://www.ti.com/ lit/an/slyt765/slyt765.pdf.

[5] J. Hagedom, „Basic calculations of a 4 switch buckboost power stage“, Texas Instruments Application Report (SLVA535B), no. January, pp. 1-13, 2018. [Online]. Available: http://www.ti.com/lit/an/slva535b/slva535b. pdf.

[6] V. Choudhary, „Under the hood of a noninverting buckboost converter", Power Supply Design Seminar, no. 17, 2016.

[7] B. Sun, R. Burgos, and D. Boroyevich, ,2 W Gate drive power supply design with PCB-embedded transformer substrate", Conference Proceedings - IEEE Applied Power Electronics Conference and Exposition - APEC, pp. 197-204, 2017. DoI: 10.1109/APEC.2017.7930693.

[8] Z. Gong, Q. Chen, X. Yang, B. Yuan, W. Feng, and Z. Wang, „Design of high power density DC-DC converter based on embedded passive substrate", PESC Record IEEE Annual Power Electronics Specialists Conference, pp. 273-277, 2008, ISSN: 02759306. DOI: 10.1109/ PESC.2008.4591939.

[9] M. T. Thompson, „Inductance Calculation Techniques - Part II: Approximations and Handbook Methods“, Power Control and Intelligent Motion, no. 1, pp. 1-11, 1999.

[10] W. G. Hurley and M. C. Duffy, „Calculation of self- and mutual impedances in planar sandwich inductors", IEEE Transactions on Magnetics, vol. 33, no. 3, pp. 22822290, 1997, ISSN: 00189464. DOI: 10.1109/20.573844.

[11] Analog Devices, ,LT8390 - 60V Synchronous 4-Switch Buck-Boost Controller with Spread Spectrum“, pp. 132, [Online]. Available: https://www.analog.com/media/ en/technical-documentation/data-sheets/1t8390.pdf.

[12] EPC, „EPC2001 Enhancement Mode Power Transistor R DS ( ON ) , 7 m W“, pp. 1-6, 2013.
[13] J. Chen and J. J. Liou, „Improved and physics-based model for symmetrical spiral inductors“, IEEE Transactions on Electron Devices, vol. 53, no. 6, pp. 13001309, 2006, ISSN: 00189383. DOI: 10.1109/TED.2006. 874089. 